\title{
Formaldehyde removal by the internal wall paint - preliminary study
}

\author{
Andrzej Szczurek ${ }^{1}$, Żaneta Zajiczek ${ }^{1}$, Dawid Sibilak ${ }^{2}$, and Monika Maciejewska, ${ }^{1, *}$ \\ ${ }^{1}$ Wroclaw University of Science and Technology, Faculty of Environmental Engineering, Wybrzeże \\ Wyspiańskiego 27, 50-370 Wroclaw, Poland \\ ${ }^{2}$ Dow Polska Sp. z o.o., Ul. Domaniewska 50A, 02-672 Warsaw, Poland
}

\begin{abstract}
Formaldehyde is an important indoor air pollutant. It is released mainly from building materials and consumer products. This contaminant has been recognized as having negative effect on humans. Recently, there are developed methods of reducing its emission as well as removal from indoor air. An example of the last approach is the functionalisation of interior wall paints. The influence of such paint on indoor air was preliminarily examined in this work. The obtained results show that, during intermittent exposures, responses of formaldehyde measurement device were lower in the room painted with functionalised paint compared with the room painted using traditional formula paint. This outcome was statistically significant in $67 \%$ of the examined cases at the significance level $\alpha=0.01$. It was found that the serious problem associated with determining the influence of functionalised paint on indoor air, in real conditions, is the low level of formaldehyde concentrations, compared with the detection limit and accuracy of the available measurement devices.
\end{abstract}

\section{Introduction}

Volatile Organic Compounds (VOCs) are airborne chemicals found in building and household products. As VOCs are released into the air, they get in contact with occupants. Many studies indicate that indoor air pollution in non-industrial buildings affects human health and productivity in a significant way. Formaldehyde is definitely the most common and the best-known indoor air pollutant. Generally speaking, exposure to this pollutant is higher indoors than outdoors. This is mainly due to stronger sources and low air exchange rates in the indoor environment [1].

Adverse health effects from exposure to formaldehyde in prefabricated houses, especially irritation of the eyes and upper airways, were first reported in the mid-1960s. Formaldehyde emissions from particle boards bonded with urea formaldehyde resin were soon identified as the cause of the complaints. Discussion about formaldehyde as a possible carcinogen started in 1980 when the carcinogenicity of formaldehyde in rats and mice after long-term inhalation exposure was reported $[2,3]$.

\footnotetext{
*Corresponding author: monika.maciejewska@pwr.edu.pl
} 
Preliminary studies showed that gaseous formaldehyde could cause carcinogenic and fatal abnormalities [4]. Clinical and epidemiological investigations have demonstrated that work-related exposure to this substance results in headaches, anxiety, fatigue, sleep disorders, in particular, cognitive disorders [5, 6]. In addition, the results of animal experiments have consistently revealed that gaseous formaldehyde exposure induced abnormal behaviours, including spatial memory deficits [7-9].

Indoor sources may be combustion processes such as smoking, heating, cooking, candle or incense burning $[10,11]$. However, major sources in non-smoking environments appear to be building materials and consumer products that emit formaldehyde $[11,12]$. This applies especially to new materials and products [13] but the emission can last several months, particularly in conditions featured by high relative humidity and high indoor temperatures [14].

Formaldehyde sources in indoor environments include: furniture and wooden products containing formaldehyde-based resins such as particleboard, plywood and medium-density fiberboard; insulating materials (in the early 1980s, urea formaldehyde foam insulation was a major source of indoor pollution); textiles; do-it-yourself products such as paints, wallpapers, glues, adhesives, varnishes and lacquers; household cleaning products such as detergents, disinfectants, softeners, carpet cleaners and shoe products; cosmetics such as liquid soaps, shampoos, nail varnishes and nail hardeners; electronic equipment, including computers and photocopiers; and other consumer items such as insecticides and paper products [15]. Hence, a large number of inhabitants are inevitably exposed to this contaminant.

Different methods are used to diminish concentration of formaldehyde inside nonindustrial buildings. Recently, paints with active components that react with formaldehyde are proposed. The aim of this paper is to determine the influence of these paints on formaldehyde concentration for better indoor air quality. The study of the problem included two major elements namely, the measurement experiment and the appropriate data analysis.

\section{Experimental study}

The experimental study consisted in intermittent measurement of formaldehyde concentration in the air of two rooms. One of them was painted with the functionalised paint and the other was painted using a paint without the functionality. As a result of this operation, the air in the first room was exposed to the impact of the functionalised paint and the air in the second room was not subject to this kind of influence.

\subsection{Materials}

Two kinds of paint were used in the study. They were: paint with functionality (further called paint $\mathrm{F}$ ) and paint without functionality (further called paint $\mathrm{O}$ ). Both paints have been formulated in similar way. Both were based on acrylic binders, more than $25 \%$ in the recipe been used. All other ingredients were very typical for premium satin and matt interior wall paint (calcium carbonate, titanium dioxide, biocides, rheology modifiers, pigments, dipsergators, defoamers and water). In paint $\mathrm{F}$, the technology used in the binder, employs a functional monomer that facilitates interaction between paint on the wall and formaldehyde in the air. The monomer bonds with the formaldehyde and transforms it into harmless products. Formaldehyde-Abatement Technology begins working as soon as paint is applied. It continues to work after paint dries. It is a breakthrough that does not just reduce paint's impact on indoor air quality — it actively helps improve it [16]. The painting was carried out by a professional service recommended by the paint producer. One layer of paint was applied by the roller. 


\subsection{Object}

Measurements were performed in two similar office rooms. The spaces involved in the study are shown schematically in Fig. 1. They are located in the same building, on the 4th floor, next to each other. Both rooms have identical volume $45 \mathrm{~m}^{3}$ and dimensions $3 \mathrm{~m} \mathrm{x} 5$ $\mathrm{m} \times 3 \mathrm{~m}$. Each of them is fitted with one window and their solar orientation is the same. The floor cover is identical in two rooms - carpet. They are furnished with a standard office furniture set, which includes desks and cabinets. Both rooms were payed for use in 2007 (10 years ago). For the preliminary study all furniture, carpets and other interior finishing materials have not been changed. Location of individual items in the two rooms was personalised (see Fig.1). Rooms are served by the air conditioning system, which is operated during office working hours.

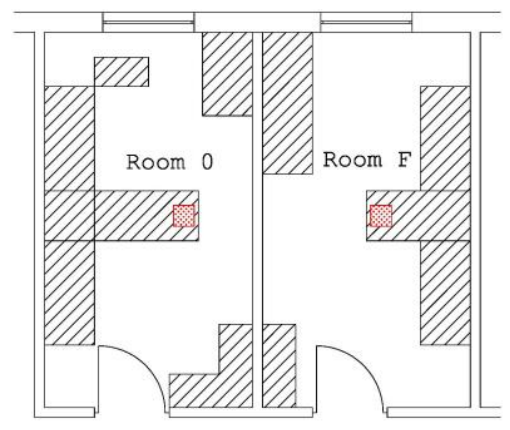

Fig. 1. Schema of rooms which were included in experiment. Room $\mathrm{O}$ was painted using paint without functionality. Room F was painted using paint with functionality. Red square indicates the location of the measurement device.

Two rooms, nearly identical, as described, were painted with different paints. Room F was painted using paint with functionality. Room $\mathrm{O}$ was painted using paint without functionality. The overall painted surface in one room was approx. $42 \mathrm{~m}^{2}$. After painting, the dominating factor which differentiated the two rooms was the impact and lack of impact of the functionalised paint on indoor air.

In the period of study, both rooms were in normal use. Due to the character of work, room occupation changed in a totally random fashion. If possible, the doors of the rooms were ajar. Windows were tilted occasionally.

\subsection{Measurement device}

The measurements were done using Formaldemeter htV-m. The device utilises electrochemical sensor manufactured by PPM Technology. Its standard measurement range is $0-10 \mathrm{ppm}\left(0-12.3 \mathrm{mg} / \mathrm{m}^{3}\right.$ at $\left.25^{\circ} \mathrm{C}\right)$. The accuracy is $10 \%$, at $2 \mathrm{ppm}$ and the precision is $2 \%$. The resolution is $0.001 \mathrm{ppm}$.

The device determines formaldehyde concentration in a $10 \mathrm{ml}$ snatch-sample of air taken by the internal pump. The recommended sampling frequency is 1 per minute or longer. In our study, the highest possible sampling frequency was used, namely 1 per minute. The response time of the device is approx. 60 seconds, when offering best accuracy. In this study, the instrument was operated in 'high accuracy mode'. Continuous mode of operation and data logging was utilised in order to assure the collection of the exhaustive measurement data set. 
The location of the device in room $\mathrm{F}$ and in room $\mathrm{O}$ is shown in Fig. 1. It was chosen to assure the accessibility of the device. The instrument was placed at the height of $1 \mathrm{~m}$, in the breathing zone of the sitting person.

\subsection{Measurement procedure}

The measurement session started 7 days after painting. Different measurement procedures were applied during the day and at night-time.

In daytime, measurements were performed intermittently in room $\mathrm{F}$ and room $\mathrm{O}$. The single data recording period in one room was set to 30 or $15 \mathrm{~min}$. The choice was arbitrary. In both rooms, the measurements were done using the same sensor device. It was realised by moving the instrument between rooms (see Fig. 1) every 30 or $15 \mathrm{~min}$. This measurement procedure was applied between 6 and 9 hours per day.

At night-time, the device remained in one room and it recorded formaldehyde concentration there. During subsequent nights, measurements were performed in different rooms.

The data presented in this work was collected in course of 4 measurement days. The analysis was focussed on the results of daytime data collection.

\section{Method of data analysis}

The objective of data analysis was to determine whether there exists a statistically significant difference between the results of formaldehyde concentration measurement in indoor air which was exposed to the influence of the paint with functionality and in indoor air which was not subject to such impact.

The analysis consisted in comparing the measurement data sets collected during intermittent exposures of the sensor device in room $\mathrm{F}$ and in room $\mathrm{O}$. The two-sample $t$-test, also called Welch's $t$-test, was applied for this purpose.

The considered null hypothesis, $H_{0}$ states that the means $\mu_{1}$ and $\mu_{2}$ in two populations are equal.

$$
H_{0}: \mu_{1}=\mu_{2}
$$

The test statistic is given by the formula

$$
t=\left(\mu_{1}-\mu_{2}\right) /\left[\left(\sigma_{1}^{2} / n_{1}\right)+\left(\sigma_{2}^{2} / n_{2}\right)\right]^{0.5}
$$

where: $\sigma_{1}{ }^{2}$ and $\sigma_{2}{ }^{2}$ are variances in the compared populations and they are assumed unequal, $\mathrm{n}_{1}$ and $\mathrm{n}_{2}$ are the sizes of samples drawn from the two populations. When the null hypotheiss (1) is true the test statistic (2) has approximately $t$-Student distribution. In case of considering one sided alternative hypothesis, $H_{A}$ which states that

$$
H_{A}: \mu_{1}>\mu_{2}
$$

there is no reason to reject the null hypothesis, at the signifcance level $\alpha$ if

$$
p\left(t>t_{\alpha, v}\right)<\alpha
$$

where $t_{\alpha, \mathrm{v}}$ is the value of $t$-Student distribution for the significance level, $\alpha$ and the number of degrees of freedom, $v$ as given by Satterthwaite's approximation.

The Welch's $t$-test was applied to compare each pair of data sets collected during subsequent esposures of sensor device in room F and in room O. Sample estimnates of $\mu_{1}$, 
$\mu_{2}$ and $\sigma_{1}{ }^{2}, \sigma_{2}{ }^{2}$ were computed using the compared measurement data sets. The significance level was assumed arbitrarily, $\alpha=0.01$.

\section{Results and discussion}

The averaged data recorded in course of the experimental study are shown in Fig. 2. It displays the mean values of the results of formaldehyde concentrations measurement during subsequent data collection periods, in room $\mathrm{F}$ and in room $\mathrm{O}$. Both sequences of measurement device location were included in the analysis, namely room $\mathrm{F}$ after room $\mathrm{O}$ and room $\mathrm{O}$ after room $\mathrm{F}$.

In Fig. 2, along the horizontal axis, there may be distinguished four sets of bars. The distinct sets include the results of the measurements done during individual days of the study. On days 1, 3 and 4 the data collection period in one room usually lasted $30 \mathrm{~min}$, while on day 2 - it was $15 \mathrm{~min}$.

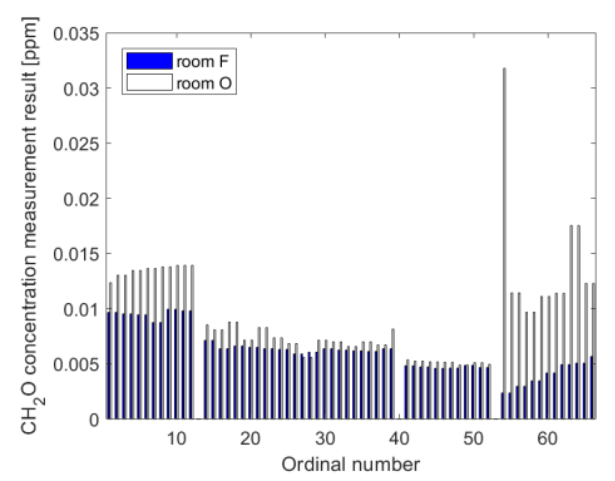

Fig. 2. Mean values of the results of formaldehyde concentration measurement during subsequent data collection periods, in room $\mathrm{F}$ and in room $\mathrm{O}$.

Based on Fig. 2, the results of formaldehyde concentration measurement in the examined office rooms were very small. It was the case irrespective of the averaging period. As shown in Fig. 2, the measurement results varied between 2 and $32 \mathrm{ppb}$ of formaldehyde. It has to be noted, that the obtained values were considerably smaller than the accuracy of the measurement device.

In the individual rooms, the results of formaldehyde concentration measurement were not constant over time. While, during one day the values remained at the similar level, there were observed day to day differences. This temporal variation was particularly well pronounced in case of room $\mathrm{O}$ which was painted with the normal paint.

In Fig. 3, there are shown the differences between the average results of measurements in room $\mathrm{F}$ and room $\mathrm{O}$, during subsequent exposure periods of the sensor device. As shown, the difference was negative just in two cases. It implies, that generally, the average result of formaldehyde concentration measurement in room $\mathrm{F}$ was greater than in room $\mathrm{O}$, during subsequent exposures. The percentage of such occurrences was $97 \%$. However, is shall be noted that the observed differences were very small, between zero and $29 \mathrm{ppb}$, as compared with the accuracy of the measurement device. 


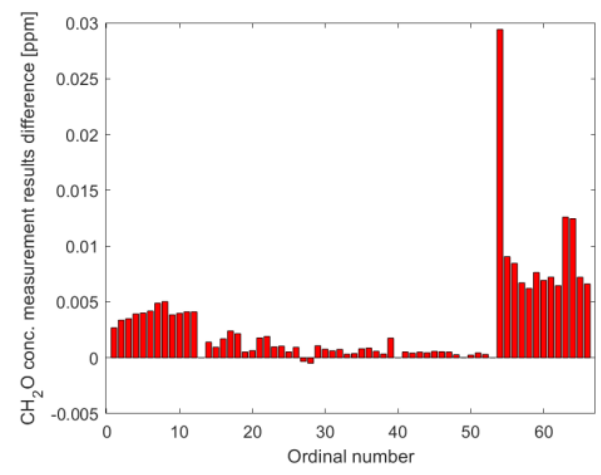

Fig. 3. Difference between the average results of measurements in room $\mathrm{F}$ and room $\mathrm{O}$ during subsequent exposure periods of the sensor device.

In Fig. 4 there are shown the results of statistical analysis of the obtained measurement results. Each bar represents the outcome of comparison between two sets of measurement data, one collected in room $\mathrm{F}$ and one recorded in room $\mathrm{O}$, during subsequent exposures. The height of the bar is the $p$-value associated with testing the hypothesis $H_{0}$, which states that the average result of formaldehyde concertation measurement is the same in the room painted using paint with functionality and in the room painted using paint without functionality.

The $p$-values displayed in Fig. 4 are the probabilities that the computed test statistic belong to $t$-Student distribution. Claiming this is synonymous with the correctness of null hypothesis. The computed $p$-values were examined versus the significance level $\alpha$, which is also shown in Fig. 3. The rejection of null hypothesis, $H_{0}$ is justified in case the $p$-value is smaller than $\alpha$.

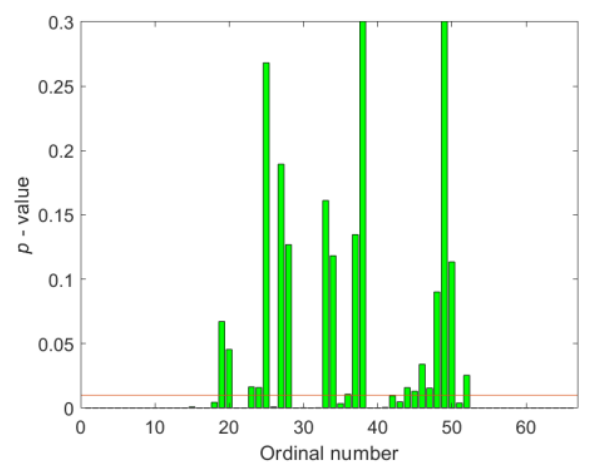

Fig. 4. $p$-values for the unpaired two-sample $t$-test.

As shown in Fig. 4, the majority of computed $p$-values are smaller than the significance level, $\alpha$. Hence, for the majority of pairs of the compared data sets, there are reasons to reject the null hypothesis about the equality of the respective mean values, at this significance level. This outcome implies, that in most cases there are reasons to claim that the results of formaldehyde concentrations measurement in two rooms were different. Moreover, considering the construction of the alternative hypothesis, $H_{A}$ it may be concluded that the values measured in room $\mathrm{F}$ were smaller than the ones recorded in room $\mathrm{O}$, at the significance level $\alpha=0.01$. Based on the obtained results, the percentage of such occurrences was $67 \%$. 
The joint analysis of Fig. 3 and Fig. 4 provides additional information in favour of the soundness of conclusions based on statistical hypothesis testing. In more than $30 \%$ of the examined cases, although there was a difference between the mean values of results of formaldehyde concentration measurement in room $\mathrm{F}$ and room $\mathrm{O}$, the difference was not statistically significant.

\section{Conclusions}

One of main problems associated with formaldehyde measurement in indoor air, in real conditions, is low concentration level of this compound. Measurement devices, which are affordable in indoor air quality assessment applications, do not offer sufficient measurement characteristics. This particularly refers to the detection limit and accuracy.

To some extent, this drawback may be fulfilled by the appropriate experimental design and data analysis. An example of such approach was presented in this work.

The experimental study was conducted in order to examine the reduction of formaldehyde concentration in indoor air by the functionalised paint. The measurements of formaldehyde concentrations were done in two similar rooms. One was painted with a functionalised paint and the other was painted using the paint without functionality. The recorded responses of the device were mostly smaller than $20 \mathrm{ppb}$. It is less than the accuracy of the measurement device.

Based on the statistical analysis of the measurement data, it was shown that the results of measurement of formaldehyde concentration in the room painted using paint with functionality were smaller compared with the results obtained in other room, intermittently. The conclusion was valid for nearly $70 \%$ of the coupled exposures, at the significance level $\alpha=0.01$.

\section{References}

1. T. Salthammer, F. Fuhrmann, S Kaufhold, B. Meyer, A. Schwarz, Indoor Air 5, 120 (1995)

2. W. D. Kerns, K. L. Pavkov, D. J. Donofrio, E. J. Gralla, J. A. Swenberg, Cancer Res. 43, 4382 (1983)

3. J. A. Swenberg, W. D. Kerns, R. I. Mitchell, E. J. Gralla, K. L. Pavkov, Cancer Res. 40, 3398 (1980)

4. M. Krzyzanowski, WHO air quality guidelines for Europe. Journal of Toxicology and Environmental Health, Part A. 71, 47-50 (2008)

5. K. H. Kilburn, R. H. Warshaw, Environmental Research 58, 134-146 (1992)

6. K. H. Kilburn, R. H. Warshaw, J. C. Thornton, Archives of Environmental Health 42, 117-120 (1987)

7. S. E. Usanmaz, E. S. Akarsu, N. Vural, Environmental Toxicology and Pharmacology 11, 93-100 (2002)

8. Y. Liu, Z. Ye, H. Luo, et al. Neuroscience Letters, 464, 113-116 (2009)

9. Z. Lu, C. M. Li, Y. Qiao, Y. Yan, X. Yang, Indoor Air, 18, 77-83 (2008)

10. International Agency for Research on Cancer, IARC Monographs on the Evaluation of the Carcinogenic Risk of Chemicals to Humans 88, (2006)

11. T . Salthammer, S. Mentese, R. Marutzky, Chemical Reviews 110, 2536-2572 (2010) 
12. T.J. Kelly, D.L. Smith, J. Satola, Environmental Science \& Technology 33, 81-88 (1999)

13. A.T. Hodgson, D. Beal, J.E.R. McIlvaine, Indoor Air 12, 235-242 (2002)

14. F. Haghighat, L. De Bellis, Building and Environment 33, 261-277 (1998)

15. D. A. Kaden, C. Mandin, G. D. Nielsen, P. Wolkoff, WHO Guidelines for Indoor Air Quality: Selected Pollutants

16. The Dow Chemical Company, Emily Parenteau 